\title{
Herpetofauna em uma área de Floresta Atlântica na Ilha Anchieta, município de Ubatuba, sudeste do Brasil
}

\author{
Paulo José Pyles Cicchi ${ }^{1,4}$, Herbert Serafim ${ }^{2,3}$, \\ Marco Aurélio de Sena ${ }^{2}$, Fernanda da Cruz Centeno ${ }^{3}$ \& Jorge Jim ${ }^{1}$ \\ IDepartamento de Zoologia, Instituto de Biociências, Universidade Estadual Paulista - UNESP, \\ CP 510, CEP 18618-000, Botucatu, SP, Brasil \\ ${ }^{2}$ Departamento de Genética e Biologia Evolutiva, Instituto de Biociências, Universidade de São Paulo - USP \\ Rua do Matão, 277, Edifício André Dreyfus, $1^{\circ}$ andar, sala 221, CEP 05508-900, São Paulo, SP, Brasil \\ ${ }^{3}$ Laboratório Especial de Ecologia e Evolução, Instituto Butantan, \\ Av. Doutor Vital Brasil, 1500, CEP 05503-900, São Paulo, SP, Brasil, http://www.butantan.gov.br/ecoevo \\ ${ }^{4}$ Autor para correspondência: Paulo José Pyles Cicchi, e-mail: paulocicchi@yahoo.com.br
}

CICCHI, P. J. P., SERAFIM, H., SENA, M. A., CENTENO, F. C. \& JIM, J. Atlantic Rainforest herpetofauna of Ilha Anchieta, an island on municipality of Ubatuba, southeastern Brazil. Biota Neotrop., 9(2): http://www.biotaneotropica.org.br/v9n2/en/abstract?inventory+bn01009022009.

\begin{abstract}
The aim of this work was to study of herpetofaunal diversity patterns in Parque Estadual da Ilha Anchieta, municipality of Ubatuba, located on the northern coast of São Paulo state, focusing: diversity, distribution and seasonal activity patterns. Data was obtained monthly from July 2005 to June 2006, in a total of 55 fieldwork days. Four sampling methods were used: visual surveys, pitfall traps, funnel traps and local collectors. Visual surveys and pitfall traps were more successful than other methods, which were complementary. A total of 17 anuran amphibians and eight reptile species were recorded. As in most studies in tropical areas, local herpetofauna presented a relatively low evenness, and differred from other communities by showing higher number of common species in relation to the rare ones. Anuran richness was higher in the closed physiognomies (deciduous and non-deciduous broadleaf forest), while reptiles richness was more representative in the anthropic field (open physiognomy). Correlation analyses showed that amphibian richness was not significantly associated with environmental parameters and reptile richness was significantly associated to temperature means. Our results demonstrate the importance of conservation of this island within the protected area of Parque Estadual da Ilha Anchieta.
\end{abstract}

Keywords: Amphibia, Reptilia, island, diversity, conservation, Atlantic Forest.

CICCHI, P. J. P., SERAFIM, H., SENA, M. A., CENTENO, F. C. \& JIM, J Herpetofauna em uma área de Floresta Atlântica na Ilha Anchieta, município de Ubatuba, sudeste do Brasil. Biota Neotrop., 9(2): http://www.biotaneotropica.org.br/v9n2/pt/abstract?inventory+bn01009022009.

Resumo: Este trabalho teve como objetivo o estudo da diversidade da herpetofauna do Parque Estadual da Ilha Anchieta, município de Ubatuba, localizada no litoral norte do estado de São Paulo, enfocando os seguintes aspectos: diversidade, distribuição e padrões de atividade sazonal. Entre julho de 2005 e junho de 2006 foram realizadas viagens mensais à ilha, totalizando 55 dias de trabalhos de campo. Para a amostragem foram utilizados os métodos busca ativa, armadilhas de interceptação e queda, armadilhas de funil e coleta por terceiros, Busca ativa e armadilhas de interceptação e queda apresentaram melhor desempenho, e os demais métodos se mostraram complementares. Foram inventariadas 17 espécies de anfíbios anuros distribuídas em oito famílias, e oito espécies de répteis das quais cinco são espécies de lagartos de quatro famílias e três de serpentes de duas famílias. Como observado na grande maioria das pesquisas em áreas tropicais, a área de estudo apresentou relativamente baixa equabilidade, porém, diferente de outras comunidades estudadas, apresentou um maior número de espécies comuns em relação às espécies raras. A riqueza de anfíbios anuros foi mais alta nas fisionomias consideradas fechadas (mata latifoliada densa e mata latifoliada rala) em relação às abertas, enquanto que a riqueza de répteis foi mais representativa no campo antrópico (fisionomia considerada aberta). A análise de correlação demonstrou que a riqueza de anfíbios não foi significativa em relação aos elementos climáticos, enquanto a riqueza de répteis foi significativamente correlacionada às médias de temperaturas máxima e mínima. A presença de inúmeras peculiaridades reforça a importância da conservação do Parque Estadual da Ilha Anchieta Palavras-chave: Amphibia, Reptilia, ilha, diversidade, conservação, Mata Atlântica. 


\section{Introdução}

A comunidade científica tem reconhecido à importância de estudos voltados ao levantamento e quantificação da diversidade biológica. Da mesma forma, estudos sobre abundância e distribuição das espécies também têm sido enfatizados por fornecerem conhecimentos básicos para pesquisas nas áreas de ecologia, sistemática, biogeografia e biologia da conservação (Heyer et al. 1994). Na literatura (e.g. Scott Jr. 1976, Duellman 1988, Fauth et al. 1989, Giaretta et al. 1997, Giaretta 1999, Sawaya 1999) estudos sobre ecologia de comunidades de anfíbios e de répteis têm chamado a atenção para a história natural das espécies que ocorrem ao longo do ambiente, padrões de diversidade, distribuição, e os processos e mecanismos que geram estes padrões.

O processo de desmatamento e perturbação das florestas tropicais no mundo não é uniforme e foi muito mais intenso em algumas regiões, como a zona costeira brasileira (Dean 1995, Ministério do Meio Ambiente 2002). A expressão Mata Atlântica sensu lato é aplicada à vegetação que ocorre ao longo do litoral brasileiro, do Rio Grande do Norte ao Rio Grande do Sul, com amplas extensões para o interior, sendo constituída pelas Florestas Ombrófilas Densa e Mista e pelas Florestas Estacionais, incluindo ainda os ecossistemas associados de manguezais, campos salinos e restingas, definidos como áreas de formações pioneiras (Veloso 1992, Joly et al. 1999). A Mata Atlântica é um dos 25 hotspots mundiais de biodiversidade, abrigando mais de 8.000 espécies endêmicas (Myers et al. 2000). O processo de substituição da vegetação nativa, principalmente da cobertura florestal, em função da expansão das atividades agropecuárias e das malhas urbanas, assim como do extrativismo, ocasionou, no interior do estado de São Paulo a fragmentação das florestas, resultando na formação de pequenas manchas ou de fragmentos isolados (Fonseca \& Rodrigues 2000). O estado de São Paulo mantém cerca de 13,94\% da cobertura vegetal nativa $(34,6$ mil km²), estando na região litorânea as áreas mais extensas (SP: SMA / IF 2005).

A existência de uma barreira oceânica faz dos ambientes insulares, um dos ecossistemas mais desafiadores para a sobrevivência de comunidades de animais e plantas (Ângelo 1989). Ilhas são ambientes intrinsecamente apelativos para estudos, pois são mais simples que continentes e oceanos, devido à visível distinção e fácil identificação das populações que nelas residem (MacArthur \& Wilson 1967). Pesquisas em ilhas possuem fundamental participação no desenvolvimento básico do entendimento a respeito de ecologia e evolução (Vitousek et al. 1995), assim, podem ser consideradas laboratórios naturais, possibilitando a simplificação do mundo natural para o desenvolvimento e teste de teorias gerais (Whittaker 1998).

O litoral do estado de São Paulo apresenta 129 formações insulares com tamanho e distância variáveis da costa (Ângelo 1989). A grande maioria destas formações é amplamente desconhecida, seja em relação à ocorrência de espécies animais e vegetais, ou a estudos mais detalhados sobre populações ou grupos de espécies. Em relação à herpetofauna, Ihering (1897) foi provavelmente o pioneiro no registro de serpentes em uma ilha paulista (Ilha de São Sebastião). Entre 1914-1915 João Florêncio Gomes do Instituto Butantan iniciou os estudos de uma nova espécie de Bothrops da Ilha da Queimada Grande, sendo descrita como Bothrops insularis por Amaral (1921). Além de algumas descrições de espécies (e.g. Amaral 1921, Luederwaldt \& Fonseca 1923, Hoge 1950, Hoge et al. 1959, Peixoto 1988, Marques et al. 2002a), informações mais detalhadas podem ser encontradas nos seguintes trabalhos: Muller (1968) apresentou uma lista preliminar da herpetofauna da Ilha de São Sebastião e Sawaya (1999) descreveu as variações de diversidade e densidade da anurofauna de serapilheira da Ilha de São Sebastião; Rebouças-Spieker (1974) e Vanzollini \& Rebouças-Spieker (1976) descreveram e discutiram variações morfológicas e reprodutivas de lagartos do gênero Mabuya do litoral e de algumas ilhas; Vieitas (1995) apresentou um levantamento de espécies para propor um plano de manejo para a Ilha do Mar Virado; Duarte et al. (1995) e Duarte (1999) relataram observações sobre a biologia de B. insularis; Marques et al. (2002b), em um artigo de divulgação sobre $B$. insularis, forneceram e discutiram aspectos gerais sobre biologia, conservação e evolução de B. alcatraz, B. jararaca e B. insularis; Cicchi et al. (2007) fizeram um levantamento das serpentes das ilhas do litoral paulista; e Centeno et al. (2008) compararam a diversidade de serpentes da Ilha de São Sebastião com a do continente, município de São Sebastião.

A Ilha Anchieta, situada no litoral norte do estado de São Paulo, possui área de 828 ha protegidos por um parque estadual. Assim como em várias regiões compreendidas pelo Domínio Morfoclimático da Floresta Atlântica (sensu Ab'Saber 1977), para o Parque Estadual da Ilha Anchieta inexistem dados ou trabalhos relacionados à herpetofauna. Tendo em vista a inexistência de dados e na tentativa de conhecer os padrões ecológicos da herpetofauna, o presente estudo teve como objetivo caracterizar a composição, riqueza e abundância relativa das espécies, descrever a distribuição nas diferentes fisionomias e caracterizar a atividade sazonal das espécies do Parque Estadual da Ilha Anchieta.

\section{Material e Métodos}

\section{1. Área de estudo}

Este estudo foi desenvolvido no Parque Estadual da Ilha Anchieta (PEIA; $23^{\circ} 27^{\prime} \mathrm{S}$ e $45^{\circ} 02^{\prime} \mathrm{W}$ ), localizado no município de Ubatuba, litoral norte do estado de São Paulo (Figura 1). Caracteriza-se como sendo um dos únicos parques insulares do Brasil totalmente em terras de domínio público, abrangendo toda a extensão da ilha. Atualmente é um dos grandes pontos turísticos da região costeira de São Paulo, recebendo cerca de 80.000 visitantes por ano (M. A. Fontes, com. pess.).

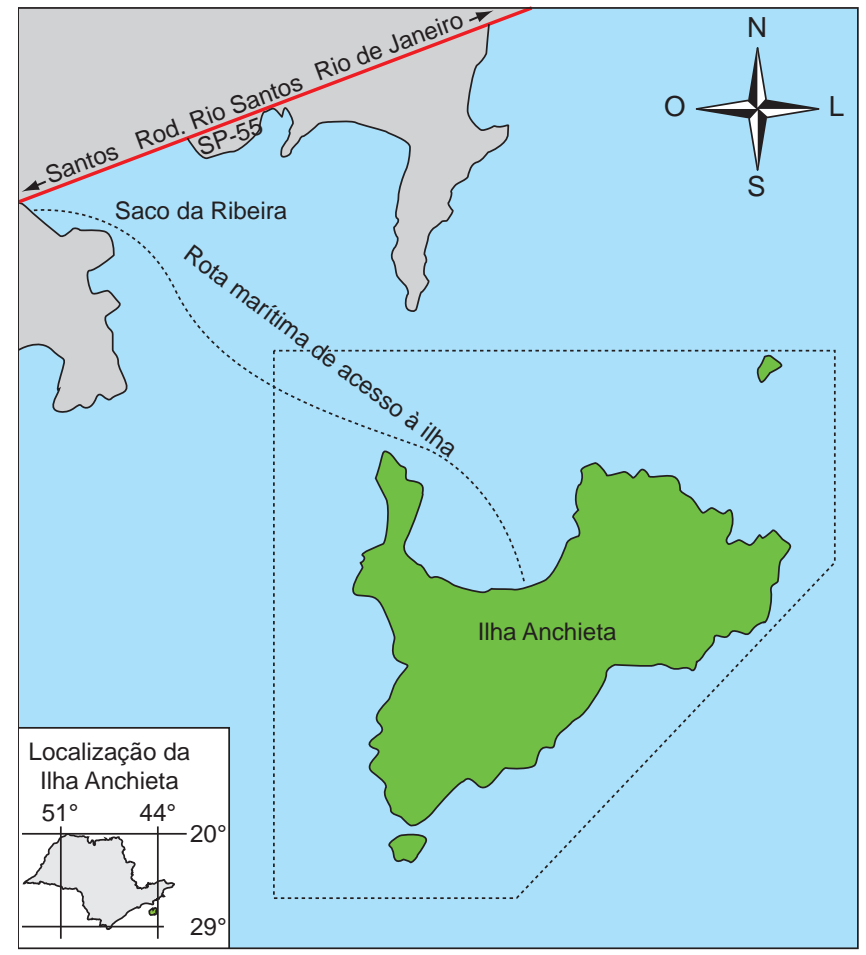

Figura 1. Mapa da região onde está compreendida a área de estudo.

Figure 1. Map of the region that is comprehended the study area. 
Segundo Veloso et al. (1991), o PEIA está inserido no Domínio da Floresta Atlântica e abriga remanescentes de Floresta Ombrófila Densa e de Restinga. A costa dessa região do Brasil mantém o mesmo nível do mar há praticamente 6.000 anos, permanecendo estável durante os últimos milênios de sua história geológica. A região também é caracterizada pela grande extensão da plataforma continental que, ao largo de Ubatuba, tem $110 \mathrm{~km}$ de largura e profundidade de quebra de aproximadamente $65 \mathrm{~m}$ (Zembruscki 1979). A Ilha Anchieta localiza-se na parte interna da plataforma e é separada do continente por um estreito canal chamado "Boqueirão", de $600 \mathrm{~m}$ de largura e $35 \mathrm{~m}$ de profundidade.

O clima da região é tipicamente tropical úmido, não apresentando estação seca (Nimer 1977). Dados de temperatura e umidade relativa do ar no PEIA foram obtidos de julho de 2005 a junho de 2006, através da Base Meteorológica do Instituto Nacional de Pesquisas Espaciais (INPE), localizada no próprio parque. A temperatura média anual foi de $23,0^{\circ} \mathrm{C}$, com temperatura média mensal mais alta ocorrendo em fevereiro $\left(26,8^{\circ} \mathrm{C}\right)$ e mais baixa no mês de julho $\left(18,3^{\circ} \mathrm{C}\right)$. A pluviosidade anual foi de $1.685,1 \mathrm{~mm}$, com valor máximo mensal em setembro (238,2 mm) e valor mínimo em agosto (47,1 mm) (Figura 2). A umidade relativa do ar apresentou média de $82,9 \%$.

Como resultado de fortes pressões antrópicas, a Ilha Anchieta compreende hoje um mosaico vegetacional composto por florestas em diferentes estádios de regeneração e formações campestres antrópicas (SP: SMA /IF 2005). Esse conjunto de fatores trouxe como conseqüência perda de apreciável parte de sua biodiversidade original. De acordo com Guillaumon et al. (1989) são identificadas para o PEIA as seguintes fisionomias: Mata Latifoliada Densa, Mata Latifoliada Rala, Gleichenial, Campo Antrópico, Restinga e Vegetação Saxícola. Para as análises deste estudo, foram utilizadas somente as fisionomias Mata Latifoliada Densa (MLD) e Mata Latifoliada Rala (MLR) (fisionomias fechadas) e Campo Antrópico (CA) e Restinga (R) (fisionomias abertas) (Figura 3).

Segundo Guillaumon \& Fontes (1992), estudos realizados sobre a vegetação da ilha demonstram a reduzida diversidade florística, em decorrência da histórica ação antrópica, principalmente relacionada ao funcionamento do presídio no início do século XX. Outro fator que pode ter influenciado na biodiversidade local foi a introdução de algumas espécies animais em 1983 (ver Guillaumon et al. 1989), sendo que alguns deles se extinguiram naturalmente, enquanto outros (e.g. Calithrix penicillata, Cebus apella, Nasua nasua e Hydrochaeris hydrochaeris) tiveram um grande crescimento populacional na ilha (Bovendorp \& Galetti 2007).

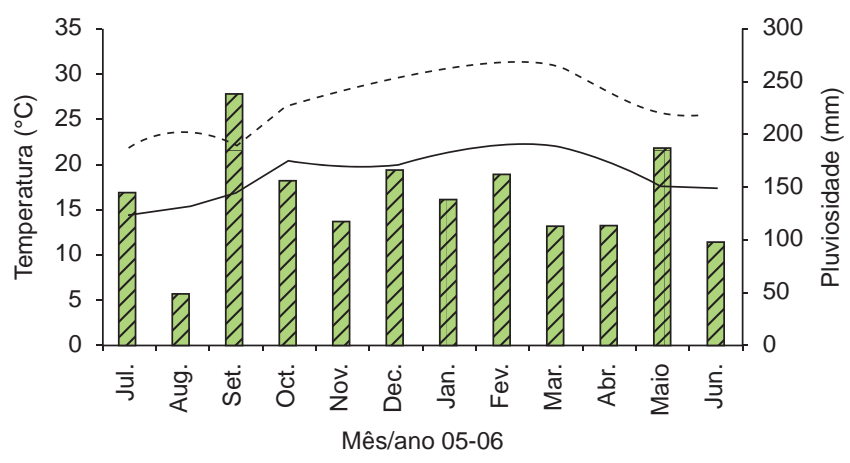

Figura 2. Temperatura máxima mensal (linha pontilhada), temperatura mínima mensal (linha contínua) e pluviosidade mensal (barras) na área de estudo entre Julho de 2005 e Junho de 2006.

Figure 2. Mean Monthly maximum temperature (dotted line), monthly minimum temperature (continuous line) and monthly rainfall (bars) at the study site between July 2005 and June 2006.

\section{Coleta de dados}

De julho de 2005 a junho de 2006 foram realizadas visitas mensais à ilha, com duração mínima de dois e máxima de sete dias, totalizando 55 dias de campo. Foram enfatizadas coletas diurnas no período matutino (entre 7:00 e 13:00 horas) e coletas noturnas (entre 17:00 e 24:00 horas). O levantamento da herpetofauna foi realizado por meio do uso de armadilhas de interceptação e queda (AIQ: "Pitfall traps with drift fence") (Heyer et al. 1994, Cechin \& Martins 2000), utilizando baldes de $35 \mathrm{~L}$ dispostos em "Y"; busca ativa (BA; Campbell \& Christman 1982, Heyer et al. 1994); armadilhas de funil (AF; Willson \& Dorcas 2004, Crosswhite et al. 1999) e coleta por terceiros (CT; Cunha \& Nascimento 1978).

Os anfíbios anuros considerados para o estudo foram aqueles já metamorfoseados, não sendo considerados os girinos. Para a captura e coleta da herpetofauna, foram percorridos transectos correspondentes às seis trilhas existentes no parque. Em cada transecto, aleatoriamente, um conjunto de AIQ foi instalado em associação com AF, totalizando 40 baldes e 30 funis em dez pontos amostrais, onde permaneceram abertos durante 55 dias não consecutivos ao longo do período de estudo. Cada ponto amostral foi verificado durante todos os dias de permanência na ilha no período da manhã. A BA foi realizada simultaneamente à verificação dos pontos amostrais e no período noturno (com início no crepúsculo), totalizando 550 horas de busca ativa, com média de três coletores por coleta. Para cada espécime encontrado, dados como substrato, atividade, coordenadas geográficas, data e horário de coleta foram registrados. Os exemplares coletados foram acondicionados em sacos plásticos e colocados dentro de isopores. Em laboratório, os indivíduos foram identificados, eutanasiados em álcool $10 \%$, etiquetados, fixados em formol $10 \%$ e conservados em álcool 70\%.

Para evitar superestimar a abundância populacional por recontagem de indivíduos ao longo do período de amostragem, os indivíduos capturados excedentes a 10 exemplares por espécie, foram marcados individualmente por amputação dos dedos e artelhos (anuros e

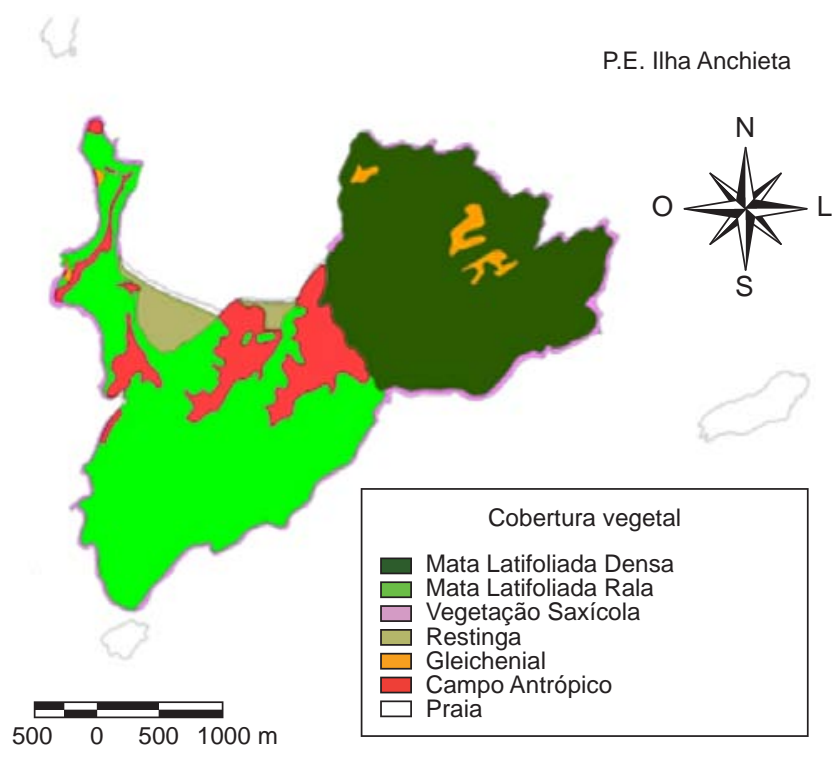

Figura 3. Mapa com a identificação das diferentes fisionomias vegetais encontradas no Parque Estadual da Ilha Anchieta. Extraído de Guillaumon et al. 1989.

Figure 3. Map with the identification of the different vegetable physiognomies founded at Parque Estadual da Ilha Anchieta. Extract from Guillaumon et al. 1989. 
lagartos; Donnelly et al. 1994) e corte de escamas (serpentes; Brown 1976), e soltos no local de captura. Espécimes recapturados não foram incluídos nas análises deste estudo, sendo registrados à parte para estudos futuros. Exemplares testemunhos foram depositados na coleção Alphonse Richard Hoge (IBSP), do Instituto Butantan, São Paulo, e Coleção de Vertebrados Dr. Jorge Jim (CVJJ), da Universidade Estadual Paulista (UNESP/Botucatu).

\section{Análise de dados}

A diversidade de espécies foi analisada em relação à riqueza (número de espécies), dominância, determinada através do índice de Berger-Parker (sensu Magurran 1988) e abundância relativa, através da porcentagem do número de indivíduos de cada espécie em relação ao total.

Foram confeccionadas curvas de rarefação de espécies (sensu Gotelli 2001) separando anfíbios e répteis. As curvas foram geradas com o programa "EstimateS" (Colwell 2005) com 1.000 aleatorizações. O programa gera 1.000 curvas de rarefação de espécies aleatorizando a ordem das amostras sem reposição; assim cada ponto da curva corresponde à média deste nas 1.000 curvas e está associado a um desvio padrão. Para a realização desta análise foram utilizados apenas os dados de BA. Cada dia de coleta ou dez horas/ dia foi considerado como uma amostra, totalizando 55 amostras ( um dia de coleta $=$ dez horas $/$ dia $=$ uma amostra).

A distribuição das espécies foi caracterizada em relação à área de ocorrência segundo as fisionomias propostas por Guillaumon et al. (1989). A similaridade na distribuição das comunidades de anfíbios e répteis nas quatro principais fisionomias foi determinada através do método da média não-ponderada, aplicado na matriz do índice de similaridade de Sörensen (IS) qualitativo, realizado no programa Cluster, versão 1.3 (desenvolvido pelo Dr. George Shepherp, do Departamento de Botânica, IB, Unicamp).

Padrões de atividade sazonal foram analisados a partir da riqueza das espécies coletadas e identificadas, desconsiderando o tipo de atividade em que se encontravam. As relações entre riqueza, pluviosidade e temperatura do ar foram analisadas através do coeficiente de correlação de Spearman (rs). Os elementos climáticos obtidos para esta análise foram organizados a partir da pluviosidade e temperaturas máxima e mínima, obtidas durante o período de coleta, e por quatro dias que as antecediam.

\section{Considerações taxonômicas}

Em virtude da enorme riqueza de espécies existente no domínio da Mata Atlântica e da posição taxonômica incerta de diversos táxons, não foi possível realizar a identificação de todos os exemplares coletados neste estudo. A identificação e a denominação das espécies aqui citadas foram baseadas na literatura atual, na comparação com espécimes depositados em coleções científicas e através de consultas a taxonomistas que têm trabalhado em localidades correlatas, considerando apenas os caracteres morfológicos. São comentadas a seguir as formas para as quais a denominação apresenta problemas ou não foi possível a aplicação de um nome científico adequado:

Flectonotus cf. goeldii - a coleta de apenas um exemplar desta espécie dificultou sua correta identificação, pois apresenta morfologia similar à de exemplares que estão depositados na coleção científica CVJJ, mas que diferem morfologicamente de exemplares tombados na Coleção de Anuros CFBH do Instituto de Biociências da Universidade Estadual Paulista, Campus de Rio Claro (CFBH).

Leptodactylus cf. marmoratus - denominação que provavelmente representa um conjunto de espécies tratadas pelo mesmo nome. No PEIA foram identificadas pelo menos duas formas diferentes, havendo a necessidade da utilização de métodos taxonômicos auxiliares (e.g. análise do canto, análises moleculares), já que a separação por caracteres morfológicos mostrouse ineficaz neste caso (C.F.B. Haddad, com. pess.).

Scinax sp. (gr. perpusillus) - o grupo não possui muitos problemas de identificação, porém várias espécies são tratadas por Scinax perpusillus. Para o PEIA, foi identificada uma forma diferente. Os caracteres que diferenciam este grupo de espécies são muito discretos, dificultando a separação e descrição apenas por caracteres morfológicos (C. A. Brasileiro, com. pess.). A utilização de análise molecular servirá como ferramenta para auxiliar na detecção de novos táxons.

\section{Resultados}

Ao longo do período amostrado, foram capturados 562 exemplares de 17 espécies de anfíbios anuros, pertencentes a nove famílias (Tabela 1 e 2) e 62 exemplares de oito espécies de répteis, pertencentes a seis famílias (Tabela 3 e 4). Entre as espécies de répteis, foi listada a espécie de quelônio Chelonoidis sp., introduzida em 1983, mas encontrada em visitas após o término do estudo e por isso não incluída na análise de dados.

Busca ativa foi a metodologia mais eficiente contemplando $100 \%$ das espécies de anuros capturados, e o maior número de indivíduos amostrados (76,15\%). Armadilha de Interceptação e Queda amostrou $29,5 \%$ das espécies e 22,6\% dos indivíduos capturados, e AF foi

Tabela 1. Anfíbios do Parque Estadual da Ilha Anchieta, Ubatuba, estado de São Paulo, Brasil.

Table 1. Amphibians from Parque Estadual da Ilha Anchieta, Ubatuba, São Paulo state, Brazil.

\begin{tabular}{l} 
Família / Espécie \\
\hline AMPHIGNATHODONTIDAE \\
Flectonotus fissilis (Miranda-Ribeiro, 1920) \\
Flectonotus cf. goeldii (Boulenger, 1895) \\
CRAUGASTORIDAE \\
Haddadus binotatus (Spix, 1824) \\
BRACHYCEPHALIDAE \\
Ischnocnema bolbodactyla (A. Lutz, 1925) \\
Ischnocnema parva (Girard, 1853) \\
BUFONIDAE \\
Rhinella ornata (Spix, 1824) \\
Dendrophryniscus brevipollicatus Jiménez de la Espada, 1871 \\
CYCLORAMPHIDAE \\
Thoropa taophora Spix, 1824 \\
HYLIDAE \\
Hypsiboas albomarginatus (Spix, 1824) \\
Scinax hayii (Barbour, 1909) \\
Scinax sp. (gr. perpusillus; A. Lutz \& B. Lutz, 1939) \\
HYLODIDAE \\
Hylodes asper (Muller, 1924) \\
Hylodes phyllodes Heyer \& Cocroft, 1986 \\
LEPTODACTYLIDAE \\
Leptodactylus cf. marmoratus (Steindachner, 1867) \\
Leptodactylus ocellatus (Linnaeus, 1758) \\
MICROHYLIDAE \\
Myersiella microps (Duméril \& Bibron, 1841) \\
\hline
\end{tabular}


Tabela 2. Matriz representando o número de espécies de anfíbios capturados por método (AIQ, AF, BA, CL) e o número total de indivíduos (N) registrados no Parque Estadual da Ilha Anchieta entre Julho de 2005 e Junho de 2006. AIQ: Armadilha de Interceptação e queda; AF: Armadilha de Funil; BA: Busca Ativa; CT: Coleta por Terceiros.

Table 2. Matrix representing the number of amphibian species captured by method (PT, FT, VES, LC) and the number of individuals (N) registered at Parque Estadual da Ilha Anchieta between July 2005 and June 2006. AIQ: Pitfall Traps; AF: Funnel Traps; BA: Visual Encounter Surveys; CT: Local Collectors.

\begin{tabular}{|c|c|c|c|c|c|}
\hline \multirow[t]{2}{*}{ Espécie } & \multicolumn{5}{|c|}{ Métodos } \\
\hline & AIQ & $\mathbf{A F}$ & BA & CL & $\mathbf{N}$ \\
\hline Flectonotus fissilis & & & 33 & & 33 \\
\hline Flectonotus cf. goeldii & & & 1 & & 1 \\
\hline Haddadus binotatus & & & 13 & & 13 \\
\hline Ischnocnema bolbodactyla & & & 6 & & 6 \\
\hline Ischnocnema parva & 2 & 1 & 39 & & 42 \\
\hline Rhinella ornata & 15 & & 25 & & 40 \\
\hline Dendrophryniscus brevipollicatus & & & 9 & & 9 \\
\hline Thoropa taophora & & & 33 & & 33 \\
\hline Hypsiboas albomarginatus & & & 89 & & 89 \\
\hline Scinax hayii & & & 63 & & 63 \\
\hline Scinax sp. (gr. perpusillus) & & & 10 & & 10 \\
\hline Hylodes asper & & & 2 & & 2 \\
\hline Hylodes phyllodes & & & 24 & & 24 \\
\hline Leptodactylus cf. marmoratus & 86 & 4 & 70 & & 160 \\
\hline Leptodactylus ocellatus & 1 & & 5 & & 6 \\
\hline Chiasmocleis carvalhoi & 23 & 1 & 5 & & 29 \\
\hline Myersiella microps & & 1 & 1 & & 2 \\
\hline Número de indivíduos & 127 & 6 & 428 & 0 & 562 \\
\hline Número de espécies & 5 & 4 & 17 & 0 & 17 \\
\hline
\end{tabular}

Tabela 3. Répteis do Parque Estadual da Ilha Anchieta, Ubatuba, Estado de São Paulo, Brasil.

Table 3. Reptiles from Parque Estadual da Ilha Anchieta, Ubatuba, São Paulo state, Brazil.

\begin{tabular}{l} 
Subordem / Família / Espécie \\
\hline SAURIA \\
PHYLLODACTYLIDAE \\
Gymnodactylus darwinii (Gray, 1845) \\
GEKKONIDAE \\
Hemidactylus mabouia (Moreau de Jonnès, 1818) \\
TEIIDAE \\
Tupinambis merianae (Duméril \& Bibron, 1839) \\
GYMNOPHTHALMIDAE \\
Placosoma glabellum (Peters, 1870) \\
SCINCIDAE \\
Mabuya caissara Rebouças-Spieker, 1974 \\
SERPENTES \\
COLUBRIDAE \\
Chironius bicarinatus (Wied, 1820) \\
Spilotes pullatus (Linnaeus, 1758) \\
BIPERIDAE
\end{tabular}

responsável pela captura de $23 \%$ das espécies e $1,06 \%$ dos indivíduos. O método CT, na coleta de anfíbios anuros, mostrou-se totalmente ineficiente neste estudo. Com relação aos répteis, BA também foi a metodologia mais eficiente, contemplando $100 \%$ das espécies e $76,66 \%$ dos indivíduos capturados, seguida por AIQ apresentando $50 \%$ das espécies e 11,66\% dos indivíduos, CT com 37,5\% das espécies e $8,33 \%$ dos indivíduos, e AF com $25 \%$ das espécies e 3,33\% dos indivíduos. As curvas de rarefação de espécies de anfíbios anuros e répteis (Figura 4) estabilizaram, indicando que, teoricamente, todas as espécies possíveis foram amostradas pelo método BA.

A anurofauna do PEIA é composta por oito espécies relativamente comuns, com contribuição percentual variando entre 5 e 30\%, duas espécies com abundância intermediária com contribuição entre 2,5 e $4 \%$ e sete espécies consideradas raras, com contribuição inferior a 2\% (Figura 5). Em relação aos répteis, cinco espécies se mostraram relativamente comuns com contribuição percentual entre 6 e $31 \%$, e três espécies foram consideradas raras com contribuição inferior a $6 \%$ (Figura 6).

A riqueza de anfíbios anuros foi mais alta nas fisionomias fechadas em relação às abertas. Das 17 espécies de anuros, 13 foram capturadas na MLR, 12 na MLD, 10 no CA e oito na R. Campo antrópico foi a fisionomia com maior abundância de anuros com 195 indivíduos capturados, seguido por MLR com 160, MLD com 139 e R apresentando 68 indivíduos. As espécies dominantes entre anuros variaram entre as fisionomias, sendo Leptodactylus cf. marmoratus dominante nas áreas de Mata, representando $56 \%$ do total para MLD e 23,75\% para MLR. No CA e R a espécie dominante foi Hypsiboas albomarginatus representando 29,2\% e 42,6\%, 
Cicchi, P. J. P. et al.

Tabela 4. Matriz representando o número de espécies de répteis capturados por método (AIQ, AF, BA, CL) e o número total (N) de indivíduos registrados no Parque Estadual da Ilha Anchieta entre julho de 2005 e junho de 2006. AIQ: Armadilha de Interceptação e queda; AF: Armadilha de Funil; BA: Busca Ativa; CT: Coleta por Terceiros.

Table 4. Matrix representing the number of reptiles species captured by method (PT, FT, VES, LC) and the number of individuals (N) registered at Parque Estadual da Ilha Anchieta between July 2005 and June 2006. AIQ: Pitfall Traps; AF: Funnel Traps; BA: Visual Encounter Surveys; CT: Local Collectors.

\begin{tabular}{lccccc}
\hline \multicolumn{1}{c}{ Espécie } & \multicolumn{3}{c}{ Métodos } \\
\cline { 2 - 5 } & AIQ & AF & BA & CT & N \\
\hline Gymnodactylus darwinii & 4 & 1 & 14 & 19 \\
Hemidactylus mabouia & 1 & & 15 & 16 \\
Tupinambis merianae & 1 & & 2 & 3 \\
Placosoma glabellum & 1 & & 2 & 3 \\
Mabuya caissara & & & 3 & 2 & 3 \\
\hline Chironius bicarinatus & & & 2 & 1 & 6 \\
Spilotes pullatus & & 1 & 5 & 2 & 8 \\
Bothrops jararacussu & & 2 & 48 & 5 & 62 \\
\hline Número de indivíduos & 7 & 2 & 8 & 3 & 8 \\
Número de espécies & 4 & & & & 4 \\
\hline
\end{tabular}
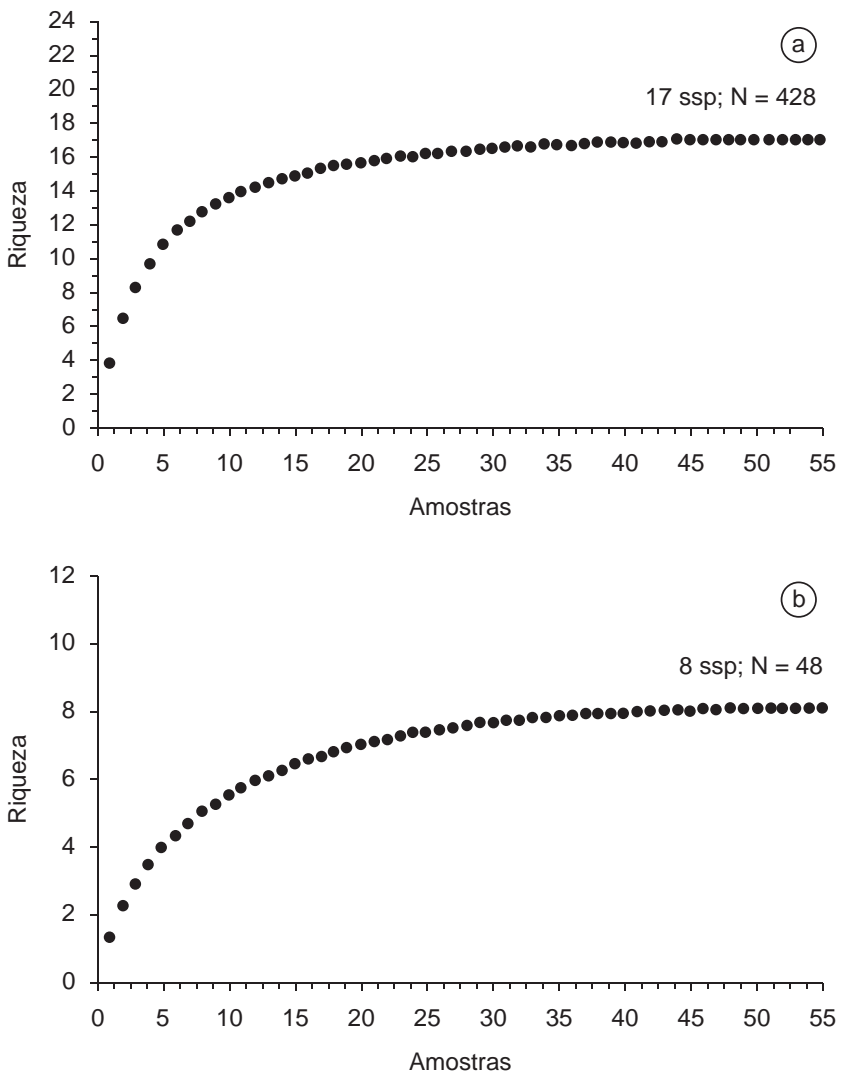

Figura 4. Curva de rarefação de espécies para 55 amostras através do método busca ativa (BA) no Parque Estadual da Ilha Anchieta. Acima da curva estão indicados o número de espécies e o total de indivíduos capturados pelo método. a) anfíbios e b) répteis.

Figure 4. Species rarefaction curve for 55 samples through visual encounter surveys (BA) method in Parque Estadual da Ilha Anchieta. Above the curve it was indicate the number of species and the total individuals captured. a) amphibians and b) reptiles.

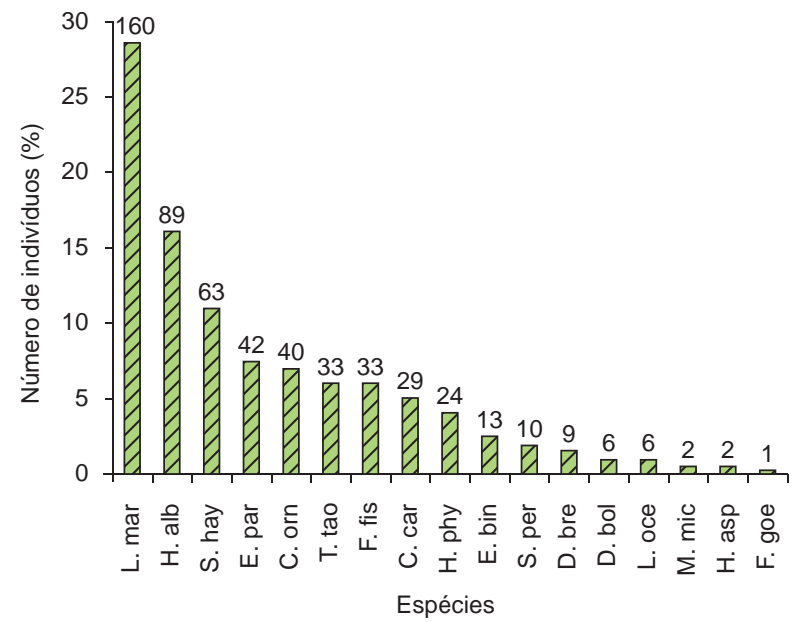

Figura 5. Abundância relativa de espécies de anfíbios em porcentagem, em relação ao número total de indivíduos $(\mathrm{n}=562)$ capturados no Parque Estadual da Ilha Anchieta. O número de indivíduos por espécie está indicado acima das barras. Legendas: L.mar = Leptodactylus cf. marmoratus; $\mathrm{H} . \mathrm{alb}=$ Hypsiboas albomarginatus $; \mathrm{S}$.hay $=$ Scina $\mathrm{x}$ hayii $; \mathrm{I}$.par = Ischnocnema parva $;$ R.orn $=$ Rhinella ornata $;$ T.tao $=$ Thoropa taophora $;$ F.fis $=$ Flectonotus fissilis; C.car $=$ Chiasmocleis carvalhoi $;$ H.phy = Hylodes phyllodes; H.bin = Haddadus binotatus; S.per = Scinax sp. (gr. perpusillus); D.bre = Dendrophryniscus brevipollicatus; I.bol = Ischnocnema bolbodactyla; L.oce $=$ Leptodactylus ocellatus; M.mic $=$ Myersiella microps $;$ H.asp $=$ Hylodes asper $;$ F.goe $=$ Flectonotus cf. goeldii .

Figure 5. Relative abundance of amphibian species in percentage of the total number of individuals $(n=562)$ captured in Parque Estadual da Ilha Anchieta. The number of individuals each species is indicated above the bars. Legend: L.mar $=$ Leptodactylus cf. marmoratus $; \mathrm{H} . \mathrm{alb}=$ Hypsiboas albomarginatus; S.hay $=$ Scinax hayii $;$ I.par = Ischnocnema parva $;$ R.orn $=$ Rhinella ornata $;$ T.tao $=$ Thoropa taophora $;$ F.fis $=$ Flectonotus fissilis $;$ C. car $=$ Chiasmocleis carvalhoi; H.phy = Hylodes phyllodes; H.bin = Haddadus binotatus; S.per $=$ Scinax sp. $($ gr. perpusillus $) ;$ D.bre $=$ Dendrophryniscus brevipollicatus; I.bol = Ischnocnema bolbodactyla $;$ L.oce = Leptodactylus ocellatus; M.mic $=$ Myersiella microps $;$ H.asp $=$ Hylodes asper $;$ F.goe $=$ Flectonotus cf. goeldii. 


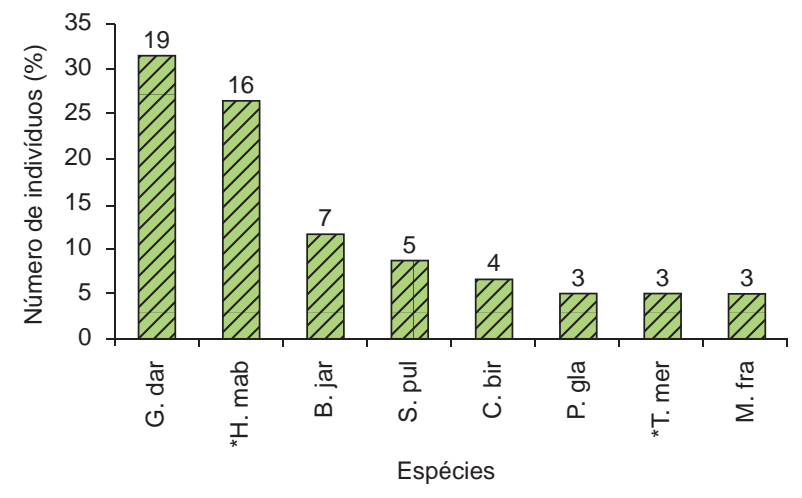

Figura 6. Abundância relativa de espécies de répteis em porcentagem, em relação ao número total de indivíduos $(\mathrm{n}=62)$ capturados no Parque Estadual da Ilha Anchieta. O número de indivíduos por espécie está indicado acima das barras. Legendas: G.dar = Gymnodactylus darwinii; H.mab = Hemidactylus mabouia $;$ B.jar = Bothrops jararacussu; S.pul $=$ Spilotes pullatus; C. bic $=$ Chironius bicarinatus $;$ P.gla $=$ Placosoma glabellum $;$ T.mer $=$ Tupinambis merianae $;$ M.cai = Mabuya caissara .

Figure 6. Relative abundance of reptile species in percentage of the total number of individuals $(n=62)$ captured in Parque Estadual da Ilha Anchieta. The number of individuals each species is indicated above the bars. Legend: G.dar = Gymnodactylus darwinii $;$ H.mab = Hemidactylus mabouia B.jar $=$ Bothrops jararacussu $;$ S.pul $=$ Spilotes pullatus $;$ C. bic $=$ Chironius bicarinatus $;$ P.gla $=$ Placosoma glabellum $;$ T.mer $=$ Tupinambis merianae $;$ M.cai = Mabuya caissara .

respectivamente. Em relação aos répteis a riqueza foi mais alta no CA, apresentando todas as espécies registradas (8 espécies), seguida de MLR (7), MLD (6) e R (3). Para a abundância relativa, o padrão foi o mesmo da riqueza, sendo CA a fisionomia com maior abundância apresentando 33 indivíduos capturados, seguido por MLR com 14, MLD com 12 e $R$ com apenas três indivíduos. Nos répteis também ocorreram variações entre as fisionomias e espécies dominantes. Nas áreas de mata as espécies dominantes variaram, sendo Gymnodactylus darwinii dominante na MLD com 50\% dos indivíduos, Hemidactylus mabouia e Bothrops jararacussu dominantes na MLR com 28,5\% cada. No CA, tanto Gymnodactylus darwinii como Hemidactylus mabouia foram dominantes, representando cada um 30,3\%. Restinga não apresentou dominância significativa entre as espécies.

Considerando a composição da anurofauna em cada fisionomia, foi observada maior similaridade entre CA e R, com 0,78\%, seguida de MLD e MLR com 0,72\% (Figura 7a). Em relação aos répteis, CA e MLR apresentaram grande similaridade entre si $(0,93 \%)$, que por sua vez apresentaram juntas alta similaridade com MLD (0,80\%). A fisionomia menos similar em relação às demais foi $\mathrm{R}$ apresentando apenas $0,54 \%$ de similaridade (Figura $7 b$ ).

A riqueza de anfíbios anuros não demonstrou correlação significativa em relação à pluviosidade ( $\mathrm{rs}=-0,018 ; \mathrm{p}=0,9558)$ e temperaturas máxima ( $r s=-0,2443 ; \mathrm{p}=0,4442)$ e mínima ( $\mathrm{rs}=-0,3053$; $\mathrm{p}=0,3345)$ no período de coleta. O maior número de espécies $(n=12)$ ocorreu nos meses de agosto e setembro de 2005, período onde as coletas foram realizadas com baixa temperatura e pluviosidade, e em janeiro de 2006, período com temperatura elevada e pluviosidade mais acentuada (Figura 8). A riqueza de espécies de répteis não demonstrou resultado significativo correlacionado à pluviosidade ( $r s=-0,0458 ; \mathrm{p}=0,8877$ ), porém foi positivamente correlacionado com temperaturas máxima e mínima no período de coleta (t.max: $r s=0,6655, p=0,0181$; t.min: $r s=0,6121, p=0,0341$ ). O pico de espécies ocorreu nos meses de janeiro $(n=7)$ e fevereiro $(\mathrm{n}=6)$, períodos mais quentes do ano (Figura 9).
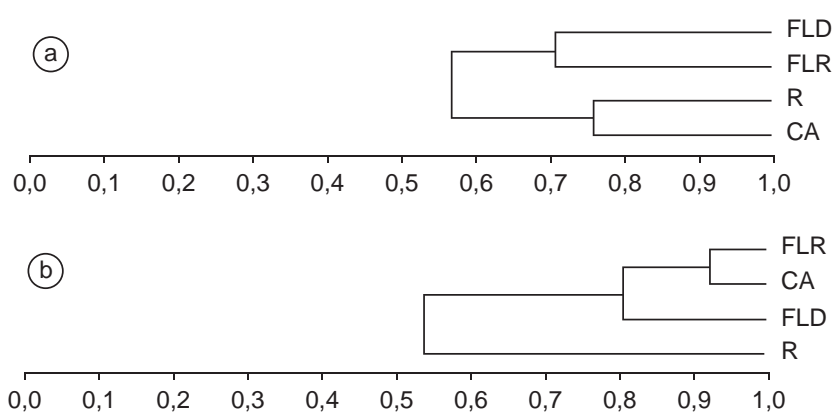

Figura 7. Dendrograma de similaridade considerando presença e ausência espécies nas quatro diferentes fisionomias no Parque Estadual da Ilha Anchieta. Legenda: MLR = Mata Latifoliada Rala; MLD = Mata Latifoliada Densa; $\mathrm{CA}=$ Campo Antrópico; $\mathrm{R}=$ Restinga. a) anfíbios e b) répteis .

Figure 7. Cluster analysis dendrogram considering the presence and absence of species between four different fisionomies in Parque Estadual da Ilha Anchieta. Legend: MLR = Sparse Latifoliade Forest; MLD = Dense Latifoliade Forest; $\mathrm{CA}=$ Antropic Field; $\mathrm{R}=$ Sandbank. a) amphibians and b) reptiles.

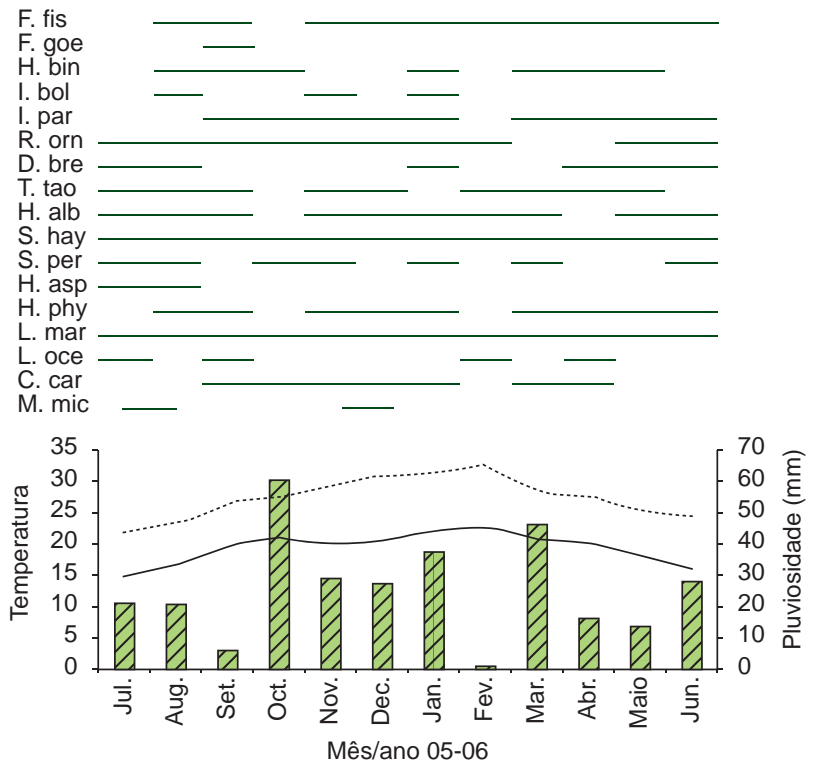

Figura 8. Relação entre riqueza de espécies de anfíbios (barras pretas na horizontal), pluviosidade mensal (barras cinzas na vertical), temperatura máxima (linha pontilhada) e temperatura mínima (linha contínua) nos períodos de coleta e quatro dias antes, entre Julho 2005 e Junho 2006 no Parque Estadual da Ilha Anchieta. Legenda: F.fis = Flectonotus fissilis; F.goe $=$ Flectonotus cf. goeldii ; H.bin = Haddadus binotatus; I.bol = Ischnocnema bolbodactyla; I.par = Ischnocnema parva $;$ R.orn $=$ Rhinella ornata $;$ D.bre $=$ Dendrophryniscus brevipollicatus $; \mathrm{T} . \mathrm{tao}=$ Thoropa taophora $; \mathrm{H} . \mathrm{alb}=$ Hypsiboas albomarginatus; S.hay = Scinax hayii; S.per = Scinax sp. $($ gr. perpusillus $) ;$ H.asp $=$ Hylodes asper $;$ H.phy = Hylodes phyllodes; L.mar = Leptodactylus $\mathrm{cf}$. marmoratus; L.oce $=$ Leptodactylus ocellatus; C.car = Chiasmocleis carvalhoi; M.mic $=$ Myersiella microps.

Figure 8. Relationship between amphibian species richness (horizontal black lines), monthy rainfall (vertical ash gray bars), maximum temperature (dotted line) and minimum temperature (continuous line) on the surveys period and four days before, between July 2005 and June 2006 in Parque Estadual da Ilha Anchieta. Legend: F.fis $=$ Flectonotus fissilis; F.goe $=$ Flectonotus $\mathrm{cf}$. goeldii $;$ H.bin = Haddadus binotatus; I.bol = Ischnocnema bolbodactyla; I.par $=$ Ischnocnema parva $;$ R.orn $=$ Rhinella ornata $;$ D.bre $=$ Dendrophryniscus brevipollicatus $; \mathrm{T} . t a 0=$ Thoropa taophora $; \mathrm{H} . \mathrm{alb}=$ Hypsiboas albomarginatus; S.hay = Scinax hayii; S.per = Scinax sp. $($ gr. perpusillus $) ;$ H.asp = Hylodes asper $;$ H.phy = Hylodes phyllodes; L.mar = Leptodactylus cf. marmoratus; L.oce = Leptodactylus ocellatus; C.car = Chiasmocleis carvalhoi; M.mic $=$ Myersiella microps . 


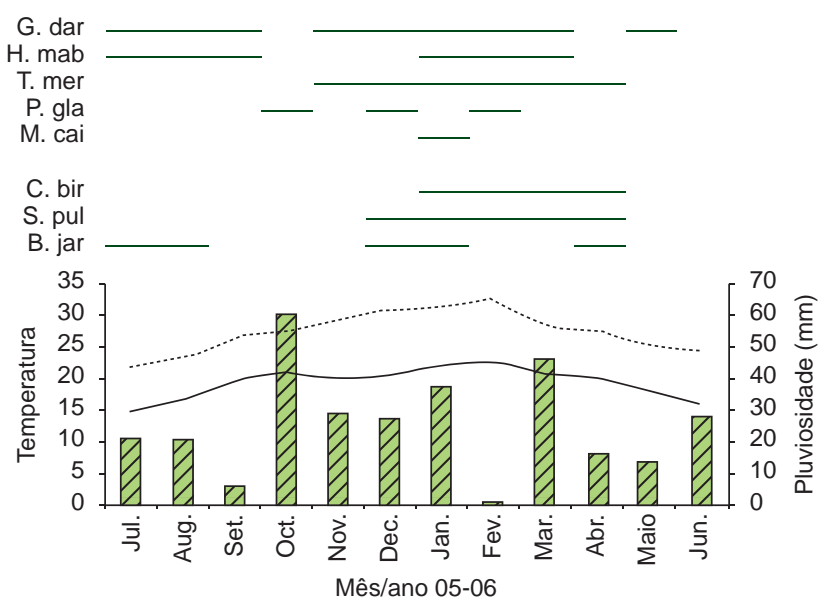

Figura 9. Relação entre riqueza de espécies de répteis (barras pretas na horizontal), pluviosidade mensal (barras cinzas na vertical), temperatura máxima (linha pontilhada) e temperatura mínima (linha contínua) nos períodos de coleta e quatro dias antes, entre Julho 2005 e Junho 2006 no Parque Estadual da Ilha Anchieta. Legenda: G.dar = Gymnodactylus darwinii $;$ H.mab = Hemidactylus mabouia; T.mer = Tupinambis merianae; P.gla = Placosoma glabellum $;$ M.cai $=$ Mabuya caissara $;$ C. bic $=$ Chironius bicarinatus; S.pul $=$ Spilotes pullatus; B.jar $=$ Bothrops jararacussu .

Figure 9. Relationship between reptile species richness (horizontal black bars), monthy rainfall (vertical ash gray bars), maximum temperature (dotted line) and minimum temperature (continuos line) on the surveys period and four days before, between July 2005 and June 2006 in Parque Estadual da Ilha Anchieta . Legend: G.dar = Gymnodactylus darwinii; $\mathrm{H} . \mathrm{mab}=$ Hemidactylus mabouia $;$ T.mer $=$ Tupinambis merianae $;$ P.gla = Placosoma glabellum; M.cai $=$ Mabuya caissara $;$ C. bic $=$ Chironius bicarinatus; S.pul $=$ Spilotes pullatus; B.jar $=$ Bothrops jararacussu .

\section{Discussão}

Conhecimentos sobre a herpetofauna do PEIA eram inexistentes, exceto pela lista de serpentes apresentada por Cicchi et al. (2007). Analisando estudos de inventário de espécies realizados em Ubatuba (e.g. Giaretta 1999, Hartmann 2004), e trabalhos desenvolvidos em outras localidades dentro do Domínio Morfoclimático da Floresta Atlântica (e.g Heyer et al. 1990, Sawaya 1999, Bertoluci \& Rodrigues 2002, Marques \& Sazima 2004, Pombal Jr. \& Gordo 2004) verificase que as espécies registradas para o PEIA não refletem a grande diversidade encontrada.

Por ser um ambiente insular, além da influência da idade e origem geológicas, que podem alterar a diversidade das espécies e a composição da biota (Darwin 1859, Vanzolini 1973, Carbonari 1981, Ângelo 1989), a teoria da biogeografia de ilhas propõe um menor número de espécies em áreas menores e mais isoladas (MacArthur \& Wilson 1967; veja revisões em Begon et al. 1986, Pianka 1994).

A histórica ação antrópica também sugere a alteração da diversidade na ilha. Guillaumon et al. (1989) relatam que no decorrer do processo de ocupação humana ocorreram grandes alterações em sua cobertura vegetal. Inúmeros estudos reportam efeitos negativos da derrubada de árvores em áreas de florestas na riqueza e abundância de anfíbios e répteis (revisão em Demaynadier \& Hunter 1995, Russel et al. 2002). Este declínio é tipicamente atribuído à perda de microhabitats proporcionados pelas áreas florestadas. Enge \& Marion (1986) ainda atribuem a baixa diversidade de répteis em áreas antropizadas à falta de refúgios e ambientes para reprodução.
Outro fator que pode ter influenciado na diversidade da ilha, foi a introdução de 14 espécies de mamíferos em março de 1983 (Guillaumon et al. 1989). Segundo Case et al. (1992), os ambientes insulares são mais vulneráveis aos impactos causados pela introdução de animais do que ambientes continentais, e registros sugerem que espécies exóticas têm causado declínios e extinções locais de espécies nativas (Brockie et al. 1988). Na Ilha Anchieta, a alta densidade de vertebrados herbívoros e predadores (Bovendorp \& Galetti 2007) está afetando diretamente o recrutamento de plantas (Fadini, 2005) e possivelmente a sobrevivência de várias espécies da fauna, como anfíbios, pássaros e répteis.

Segundo Melo et al. (2003), a riqueza (presumida) de espécies é fortemente correlacionada ao esforço de amostragem. Assim, quanto maior for o número de indivíduos capturados, maior será a riqueza de espécies observada. Esta relação é clara quanto ao número de espécies e indivíduos observados e coletados por BA, porém, não corresponde à captura através de $\mathrm{AIQ}$, principalmente com relação à anurofauna, pois este método é bem tendencioso para a fauna suscetível ao mesmo (Greenberg, et al. 1994). Neste caso, somente são amostrados animais que se deslocam pelo chão, pela camada mais superficial do solo ou ainda animais cujo tamanho não permite a fuga da armadilha. Animais que se deslocam principalmente pela vegetação ou por camadas mais profundas do solo são raramente amostrados. Além do tamanho, o comportamento dos animais também pode influenciar no sucesso de captura, como por exemplo, animais sedentários ou caçadores de espreita (Cechin \& Martins 2000). De fato, AIQ apresentou-se mais eficiente apenas para animais terrícolas e semi-fossoriais. Busca ativa mostrou ser a metodologia mais eficiente, pois abrangeu maior variedade de ambientes. Segundo Heyer et al. (1994), o método "Visual Encounter Surveys" (VES) amostra todas as espécies visíveis, sendo utilizada com eficiência em espécies que habitam ambientes facilmente identificados. Porém apresenta restrições quanto a ambientes fossoriais ou ao dossel da floresta. As outras duas metodologias empregadas neste estudo (AF e CT) se mostraram menos eficientes quando comparadas com BA e AIQ. Porém, muitos pesquisadores demonstram que apenas o uso de um único método de amostragem não é suficiente para inventariar uma área. Todos os métodos possuem suas vantagens e desvantagens que precisam ser exploradas para um inventário adequado de uma determinada região. Apesar de ter sido pouco representativa na ilha, AF, utilizada em associação com AIQ, apresentou-se importante na captura de alguns exemplares, como Myersiella microps, animal considerado raro na ilha, e um exemplar adulto de Bothrops jararacussu.

A partir de BA foram confeccionadas curvas de rarefação de espécies para a herpetofauna do Parque Estadual da Ilha Anchieta. As curvas para anfíbios e répteis atingiram um platô, indicando que provavelmente todas as espécies possíveis de serem capturadas por esta metodologia foram registradas, e como foi o método mais eficiente, extrapolamos seus resultados para o número total da herpetofauna da ilha. As curvas foram bastante informativas, não se limitando a indicar que todas as espécies foram capturadas ou com quantas amostras isto ocorreu. O formato das curvas permitiu uma boa interpretação do desempenho do método utilizado. A curva de anfíbios apresentou um crescimento mais rápido, provavelmente porque exigiu um menor esforço amostral para o acréscimo de novas espécies, enquanto que para os répteis, pela dificuldade de encontrá-los devido aos hábitos secretivos (na maioria das espécies) ou ainda pela baixa diversidade, o esforço foi mais alto e o acréscimo de novas espécies ocorreu mais lentamente.

Segundo Duellman \& Trueb (1994), dados disponíveis sobre comunidades de anuros indicam que a equitabilidade geralmente é baixa tanto nas zonas temperadas como nas tropicais, e que decresce com a altitude nas regiões tropicais. Os autores dão como exemplo uma 
comunidade de anuros na floresta de Borneo, em que a espécie mais abundante é representada por, pelo menos, o dobro de indivíduos em relação à segunda espécie mais abundante. Os autores citam ainda, o caso de Santa Cecília no Equador, onde foram registradas 81 espécies, onde as cinco mais abundantes representam $22 \%$ do número total de indivíduos, e as cinco menos abundantes somente $0,1 \%$ do total. A abundância de espécies de anfíbios anuros e de répteis do Parque Estadual da Ilha Anchieta segue um padrão que não difere muito daquele discutido por Duellman \& Trueb (1994). A área de estudo apresenta relativamente baixa equabilidade, onde as três espécies dominantes entre os anfíbios anuros representam mais da metade $(55,5 \%)$ do número de indivíduos registrados para a anurofauna, e as duas espécies dominantes entre os répteis representam $56,4 \%$ do número de indivíduos registrados. Diferente de outras comunidades estudadas (Haddad \& Sazima 1992, Jim 1980, Rossa-Feres 1997, Pombal Jr. 1997), e diferente do que é esperado para a maioria das comunidades (Krebs 1989), o Parque Estadual da Ilha Anchieta apresenta um maior número de espécies comuns, em relação às espécies raras, tanto para anfíbios como para répteis. Por se tratar de um ambiente insular, as espécies consideradas mais vulneráveis têm grande chance de estarem ausentes quando comparadas aos ambientes continentais. Segundo Woinarski \& Gambold (1992), a maioria das espécies comuns que ocorrem em ilhas, possui ampla extensão de habitats. Espécies com necessidade de hábitos específicos são pouco registradas ou são ausentes em ilhas.

Em relação à similaridade entre as fisionomias analisadas e a anurofauna, observamos a presença de certa especificidade na utilização de habitats com características distintas (e.g. "espécies de interior de mata" e "espécies de área aberta"), sendo que das 17 espécies inventariadas, apenas três foram encontradas em todas as fisionomias. Em estudos de uma comunidade de anfíbios no Paraná, Conte \& Machado (2005) também demonstraram através da análise de similaridade, a especificidade das espécies quanto ao uso de ambientes abertos e de mata. Ainda neste estudo, a similaridade e o conseqüente agrupamento entre os ambientes com características distintas foi baixa $(0,15 \%)$ se comparada à Ilha Anchieta $(0,58 \%)$. A alta similaridade entre áreas abertas (R e CA) e áreas de mata (MLD e MLR) é um forte indício de que a ação antrópica degradou parte da ilha, acarretando considerável homogeneização das diferentes fisionomias. Em outro estudo realizado na Mata Atlântica em Londrina (PR) Machado et al. (1999), consideraram espécies de anfíbios anuros de mata como indicativos do grau de conservação deste habitat.

A similaridade entre as fisionomias e os répteis, demonstrou ser diferente da análise entre fisionomias e anurofauna. Comparados aos índices obtidos pelas comunidades de anuros, os índices obtidos para os répteis foram mais semelhantes entre si. Os valores foram mais altos e os agrupamentos foram diferentes, apresentando menor especificidade entre habitats com características distintas. A homogeneização das fisionomias devido à ação antrópica, apesar de também ter sido evidenciada para a anurofauna, foi mais clara nos répteis devido aos altos valores apresentados. Dixo (2005) mostrou que a fauna de lagartos de serrapilheira se mostra muito mais sensível aos efeitos de fragmentação da mata que a fauna de anfíbios de serrapilheira.

O padrão de distribuição de riqueza de anfíbios obtido neste estudo corresponde ao observado em regiões com clima não sazonal (Crump 1974, Duellman 1978), não ocorrendo correlação entre precipitação pluviométrica e riqueza de espécies, e entre a média de temperatura mensal e riqueza de espécies. Hartmann (2004) apresentou dados diferentes para o continente próximo, onde existiu correlação entre a riqueza de espécies de anfíbios anuros e os dados climáticos. O estudo ainda demonstra que existe sazonalidade no continente, considerando os meses de outubro a abril como estação chuvosa (média superior a $200 \mathrm{~mm}$ ) e os meses de maio a setembro como estação seca ou menos chuvosa (80-160 mm). Pombal Jr. (1997) sugeriu que a não correlação significativa entre a atividade de anfíbios e os fatores climáticos pode existir devido a um conjunto de fatores. A distância entre a Serra do Mar e o Parque Estadual da Ilha Anchieta pode ter influência nestas diferenças significativas entre as variáveis bióticas e abióticas, afetando o padrão sazonal e, consequentemente, o padrão de atividade das espécies (P.J.P. Cicchi, obs. pess.). Durante o período de estudo (julho de 2005 a junho de 2006), a pluviosidade e a temperatura podem ter sido atípicas em relação aos outros anos. Ou ainda, o menor número de espécies com atividade incentivada pelas variáveis climáticas aqui consideradas, talvez tenha exercido influência na correlação significativa entre as espécies e as variáveis ambientais, como observado em outros estudos realizados em locais florestados, onde não ocorreram correlações entre atividade de vocalização de anuros e os elementos climáticos (e.g. Pombal Jr. 1997, Bernarde \& Anjos 1999).

Muitos fatores relacionados a condições climáticas podem ser responsáveis por padrões observados nos répteis (Marques et al. 2000). Segundo Martins (1994) a disponibilidade de alimento ao longo do ano é um dos fatores que deve ser considerado para explicar os padrões de atividade das serpentes. A disponibilidade de vários roedores, presas potenciais de espécies como S. pullatus e B. jararacussu (Marques 1998) é baixa, uma vez que não são vistos em abundância durante o ano todo na maioria dos ambientes já estudados de Mata Atlântica (Olmos 1991). A disponibilidade da grande maioria das espécies de anfíbios, alimento importante para Chironius spp. (Marques 1998), é considerada alta na primeira parte da estação chuvosa e sua atividade reprodutiva também está associada a este período sazonal no bioma (Bertoluci 1998).

No PEIA, a grande maioria dos anfíbios não possui padrão de ocorrência, sendo contínuo ou esporádico durante o ano. Os roedores também não apresentaram diferenças em sua abundância ao longo do ano, observado através de capturas por AIQ (P.J.P. Cicchi, obs. pess.), sendo extrapolado para a grande maioria das espécies animais que servem de alimento para os répteis. Com isso, podemos supor que a atividade da maioria dos répteis, correlacionada positiva e significativamente com a média de temperaturas máxima e mínima nos períodos de coleta, e apenas à média de temperatura máxima mensal, ocorre devido à atividade reprodutiva. Segundo Marques \& Sazima (2003), atividades como produção de espermatozóides e ovo, desenvolvimento de embriões e o ato reprodutivo, processam-se mais eficazmente em temperaturas elevadas.

Considerando apenas a região sudeste do país, o conhecimento sobre a composição de espécies, ou qualquer outra informação sobre história natural e ecologia, ainda é escasso. Nenhuma das espécies registradas para o Parque Estadual da Ilha Anchieta encontra-se na lista brasileira de espécies ameaçadas, elaborada pelo Ibama (2003). Entretanto a lista do Decreto $N^{\circ} 42.838$, de 1998 da Secretaria do Meio Ambiente do estado de São Paulo, inclui a espécie de lagarto Mabuya caissara como vulnerável. A presença de espécimes aos quais não foi possível aplicar um nome adequado (ver Comentários Taxonômicos) pode indicar a presença de táxons desconhecidos pela ciência, possivelmente endêmicos ao PEIA.

Cicchi et al. (2007), trabalhando com dados de coleções herpetológicas, indicaram registros antigos de Bothops jararaca na coleção do Instituto Butantan para a Ilha Anchieta, espécie não detectada neste estudo. Os autores documentaram tanto um caso de extinção insular, na Ilha Monte de Trigo, como a coleta após mais de quarenta anos de um exemplar de B. jararacussu na Ilha do Bom Abrigo, de modo que a presença ou extinção da população de $B$. jararaca no PEIA ainda é uma questão a ser estudada. Estudos têm demonstrado que a estabilidade da fauna e flora insular é bastante frágil (Ângelo, 1989, Vitousek et al. 1995, Losos et al. 1997, Schoener et al. 2001), o que aumenta a possibilidade de extinções e reforça a sua importância para políticas de conservação. 
Uma Unidade de Conservação como o PEIA tem como finalidade resguardar o sítio geomorfológico, o habitat e suas espécies associadas, sejam elas de interesse científico, educacional ou recreativo. Além disso, deve conter características naturais únicas e se constituir em atração significativa para o público, conservando ao máximo o seu estado natural. Os impactos ambientais ocorridos com maior intensidade no passado, ainda têm reflexos no equilíbrio ambiental nos dias de hoje. Por isso, torna-se necessário conhecer a fauna insular e a fauna continental adjacente a ilha, buscar compreender os impactos dos mamíferos introduzidos, assim como buscar práticas para subsidiar o adequado manejo de seu ambiente, visando restabelecer ao máximo o ambiente natural e assim justificar o enquadramento do PEIA como uma unidade de conservação.

\section{Agradecimentos}

Gostaríamos de agradecer à direção do Parque Estadual da Ilha Anchieta, V. Buchianeri, M. J. Robim e H. Folegatti pelo apoio à este estudo; a I. Martins e D. Peccinini-Seale revisaram cuidadosamente e fizeram sugestões e críticas que melhoram a versão previa do manuscrito; C. F. B. Haddad e M. Trefaut pela identificação de todas as espécies; Aos assessores pela revisão cuidadosa deste manuscrito; e por fim, somos muito gratos a S. C. Almeida e D. G. Scarpelini que, generosamente, prestaram auxílio no trabalho de campo. Este trabalho foi financiado pelo Conselho Nacional de Desenvolvimento Científico e Tecnológico (CNPq; Processo 130265/2006-3).

\section{Referências Bibliográficas}

AB'SABER, A.N. 1977. Os domínios morfoclimáticos na América do Sul: primeira aproximação. Geomorfologia, 52:1-21.

AMARAL, A. 1921. Contribuição para o conhecimento dos ofídeos do Brasil. A. Parte I. Descrição de uma nova espécie. Mem. Inst. Butantan, 1(1):19-37.

ÂNGELO, S. 1989. Ilhas do litoral paulista. Secretaria do Meio Ambiente - SMA, São Paulo.

BEGON, M., HARPER, J.L. \& TOWNSEND, C.R. 1986. Ecology, individuals, populations and communities. 3 ed. Blackwell Science, London.

BERNARDE, P.S. \& ANJOS, L. 1999. Distribuição espacial e temporal da anurofauna no Parque Estadual Mata dos Godoy, Londrina, Paraná, Brasil (Amphibia: Anura). Comun. Mus. Ciênc. Tecnol. PUCRS. Ser. Zool. 12:127-140.

BERTOLUCI, J. 1998. Annual patterns of breeding activity in Atlantic rainforest anurans. J. Herpetol. 32(4):607-611.

BERTOLUCI, J. \& RODRIGUES, M.T. 2002. Utilização de habitats reprodutivos e micro-habitats de vocalização em uma taxocenose de anuros (Amphibia) da Mata Atlântica do sudeste do Brasil. Pap. Avul. Zool. 42(11): 287-297.

BOVENDORP, R.S. \& GALETTI, M. 2007. Density and population size of mammals introduced on a land-bridge island in southeastern Brazil. Biol. Inv. 9(1):353-357.

BROCKIE, R.E., LOOPE, L.L., USHER, M.B. \& HAMANN, O. 1988. Biological invasions of island nature preserves. Biol. Conserv. 44(1-2):9-36.

BROWN, W.S. 1976. A ventral scale clipping system for permanently marking snakes (Reptilia, Serpentes). J. Herpetol. 10(3):247-249.

CAMPBELL, H.W. \& CHRISTMAN, S.P. 1982. Field techniques for herpetofaunal community analysis. In Herpetological communities: a symposium of the Society for the Study of Amphibians and Reptiles and the Herpetologist's League (N.J. Scott Jr, ed.). U.S. Fish Wild. Serv. Wildl. Res. Rep. 13.

CARBONARI, M.P. 1981. Caderno de Ciências da Terra. Ecossistema Insular: importância de seu estudo. Universidade de São Paulo, São Paulo.
CASE, T.J., BOLGER, D.T. \& RICHMAN, A.D. 1992. Reptilian extinctions: the last ten thousand years. In Conservation Biology (P.L. Fiedler \& S.K. Jain, eds.). Chapman \& Hall, New York, p. 91-125.

CECHIN, S.Z. \& MARTINS, M. 2000. Eficiência de armadilhas de queda (Pitfall traps) em amostragens de anfíbios e répteis no Brasil. Rev. Bras. Zool. 17(3):729-749.

CENTENO, F.C., SAWAYA, R.J. \& MARQUES, O.A.V. 2008. Snake assemblage of Ilha de São Sebastião, southeastern Brazil: comparison to mainland. Biota Neotrop. 8(3):63-68.

CICCHI, P.J.P., SENA, M.A., PECCININI-SEALE, D.M. \& DUARTE, M.R. 2007. Snakes from coastal islands of State of São Paulo, Southeastern Brazil. Biota Neotrop. 7(2):227-240.

COLWELL, R.K. 2005. EstimateS (version 7.5 b1.) - Statistical estimation of species richness and shared species from samples. University of Connecticut. Disponível em: 〈http://viceroy.eeb.uconn.edu/estimates〉.

CONTE, C.E. \& MACHADO, R.A. 2005. Riqueza e distribuição espacial e temporal em comunidade de anuros (Amphibia, Anura) em uma localidade de Tijucas do Sul, Paraná, Brasil. Rev. Bras. Zool. 22(4):940-948.

CROSSWHITE, D.L., FOX, S.F. \& THILL, R.E. 1999. Comparison of methods for monitoring reptiles and amphibians in Upland Forest of the Ouachita Mountains. Proc. Okla. Acad. Sci. 79:45-50.

CRUMP, M.L. 1974. Reproductive strategies in a tropical anuran community. Museum of Natural History, London.

CUNHA, O.R. \& NASCIMENTO, F.P. 1978. Ofídios da Amazônia X - As cobras da região leste do Pará. Publ. Avulsas. Mus. Para. Emílio Goeldi 31:1-218.

DARWIN, C.R. 1859. On the origin of species by means of natural selection. 8 ed. Oxford University Press, Londres.

DEAN, W. 1995. With broadax and firebrand: the destruction of the Brazilian atlantic forest. University of California Press, Berkeley.

DEMAYNADIER, P.G. \& HUNTER Jr., M.L. 1995. The relationship between forest management and amphibian ecology: a review of the North American literature. Environm. Rev. 3:230-261.

DIXO, M.B. 2005. Diversidade de sapos e lagartos de serrapilheira numa paisagem fragmentada do Planalto Atlântico de São Paulo. Tese de doutorado, Universidade de São Paulo, São Paulo.

DONNELLY, M.A., GUYER, G., JUTERBOCK, J.E. \& ALFORD, R.A. 1994. Techniques for marking amphibians. In Measuring and monitoring biological biodiversity: standard methods for amphibians (W.R. Heyer, M.A. Donnely, R.W. McDiarmid, L.A. Hayek \& M. Foster, eds.). Smithsonian Institution Press, Washington.

DUARTE, M.R. 1999. Microhabitat e relações térmicas da jararaca ilhoa, Bothrops insularis (Serpentes - Viperidae). Dissertação de Mestrado, Universidade Estadual Paulista, Botucatu.

DUARTE, M.R., PUORTO, G. \& FRANCO, F.L. 1995. A biological survey of the pitviper Bothrops insularis Amaral (Serpentes, Viperidae): an endemic and threatened offshore island snake of southeastern Brazil. Stud. Neotrop. Fauna Environm. 30(1):1-13.

DUELLMAN, W.E. 1978. The biology of an equatorial herpetofauna in Amazonian Ecuador. Misc. Publ. Mus. Nat. Hist. Univ. Kansas 65:1-352.

DUELLMAN, W.E. 1988. Patterns of species diversity in anuran amphibians in the american tropics. Ann. Missouri Bot. Gard. 75(1):79-104.

DUELLMAN, W. \& TRUEB, L. 1994. Biology of amphibians. McGraw-Hill Book Company, New York.

ENGE, C.H. \& MARION, W.R. 1986. Effects of clearcutting and site preparation on herpetofauna of a north Florida flatwoods. For. Ecol. Manage. 14(3):177-192.

FADINI, R. 2005. O efeito da perda de aves frugívoras sobre a dispersão de sementes e o recrutamento do palmito Euterpe edulis. Dissertação de Mestrado, Universidade Estadual Paulista, Rio Claro.

FAUTH, J.E., CROTHER, B.I. \& SLOWINSKI, J.B. 1989. Elevation patterns of richness evenness and abundance of the Costa Rican leaf-litter herpetofauna. Biotropica, 21(2):178-185. 
FONSECA, R.C.B. \& RODRIGUES, R.R. 2000. Análise estrutural e aspectos do mosaico sucessional de uma floresta semidecídua em Botucatu, SP. Sci. For. 57:27-43.

GIARETTA, A.A. 1999. Diversidade e densidade de anuros de serapilheira num gradiente altitudinal na Mata Atlântica costeira. Tese de doutorado, Universidade de Campinas, Campinas.

GIARETTA, A.A., SAWAYA, R.J., MACHADO, G., ARAÚJO, M.S., FACURE, K.G., MEDEIROS, H.F. \& NUNES, R. 1997. Diversity and abundance of litter frogs at altitudinal sites at Serra do Japi, Southeastern Brazil. Rev. Bras. Zool. 14(2):341-346.

GOTELLI, N.J. 2001. Quantifying biodiversity: procedures and pitfalls in the measurement and comparison of species richness. Ecol. Lett. 4(4):379-391.

GREENBERG, C.H., NEARY, D.G. \& HARRIS, L.D. 1994. A comparison of herpetofaunal sampling effectiveness of pitfall, single-ended and doubleended funnel traps used with drift fences. J Herpetol. 28(3):319-324.

GUILLAOUMON, J.R., MARCONDES, M.A.P., NEGREIROS, O.C. MOTA, I.S., EMMERICH, W., BARBOSA, A.F., BRANCO, I.H.D.C., CÂMARA, J.J.C., OSTINI, S., PEREIRA, R.T.L., SCORVO FILHO, J.D., SHIMOMICHI, P.Y., SILVA, D.A., MELO NETO, J.E. 1989. Plano de manejo do Parque Estadual da Ilha Anchieta. IF-Série Registros, São Paulo.

GUILLAUMON, J.R. \& FONTES, M.A. 1992. Estudo para manejo dos campos antrópicos do Parque Estadual da Ilha Anchieta - Zona de Recuperação. In Anais do $2^{\circ}$ Congresso Nacional sobre Essências Nativas. Unipress, São Paulo.

HADDAD, C.F.B. \& SAZIMA, I. 1992. Anfíbios anuros da Serra do Japi In História natural da Serra do Japi: ecologia e preservação de uma área florestal no Sudeste do Brasil (L.P.C. MORELLATO, org.). Editora da Unicamp; FAPESP, Campinas, p. 188-210.

HARTMANN, M.T. 2004. Biologia reprodutiva de uma comunidade de anuros (Amphibia) na Mata Atlântica (Picinguaba, Ubatuba, SP). Tese de Doutorado, Universidade Estadual Paulista, Rio Claro.

HEYER, W.R., RAND, A.S., CRUZ, C.A.G., PEIXOTO, O.L. \& NELSON, C.E. 1990. Frogs of Boracéia. Arq. Zool. 31(4):231-410.

HEYER, W.R., DONNELY, R.W., McDIARMID, R.W., HAYEK, L.C. \& FOSTER, M.S. (Eds.). 1994. Measuring and monitoring biological diversity: standard methods for amphibians. Smithsonian Institution Press, Washington.

HOGE, A.R. 1950. Notas erpetológicas 7. Fauna erpetológica da Ilha de Queimada Grande. Mem. Inst. Butantan. 22:151-172.

HOGE, A.R., BELLUOMINI, H.E., SCHREIBER, G. \& PENHA, A.M. 1959 Sexual abnormalities in Bothrops insularis (Amaral, 1921). Mem. Inst. Butantan. 29:17-88.

Instituto Brasileiro do Meio Ambiente e dos Recursos Naturais Renováveis IBAMA. 2003. Lista nacional das espécies da fauna brasileira ameaçadas de extinção. Disponível em: http://www.mma.gov.br/port/sbf/fauna/index. cfm (último acesso em 06/11/2007).

IHERING, H.V. 1897. A Ilha de São Sebastião. Rev. Mus. Paul. 2:129-171.

JIM, J. 1980. Aspectos ecológicos dos anfíbios registrados na região de Botucatu, São Paulo (Amphibia, Anura). Tese de Doutorado, Universidade de São Paulo, São Paulo.

JOLY, C.A., AIDAR, M.P.M., KLINK, C.A., McGRATH, D.G., MOREIRA, A.G., MOUTINHO, P., NEPSTAD, D.C., OLIVEIRA, A.A., POTT, A., RODAL, M.J.N. \& SAMPAIO, E.V.S.B. 1999. Evolution of the Brazilian phytogeography classification systems: implications for biodiversity conservation. Cienc. cult. 51(5-6):331-348.

KREBS, C.J. 1989. Ecological methodology. Harper and Row Publishers, New York.

LOSOS, J.B., WARHEIT, K.I. \& SCHOENER, T.W. 1997. Adaptative differentiation following experimental island colonization in Anolis Lizards. Nature, 387(6628):70-73.

LUEDERWALDT, H. \& FONSECA, J.P. 1923. A ilha de alcatrazes. Rev. Mus. Paul. 13:441-512.
MacARTHUR, R.H. \& WILSON, E.O. 1967. The theory of island biogeography. Princeton University Press, Princeton.

MACHADO, R.A., BERNARDE, P.S., MORATO, S.A.A. \& ANJOS, L. 1999. Análise comparada da riqueza de anuros entre duas áreas com diferentes estados de conservação no Município de Londrina, Paraná, Brasil (Amphibia, Anura). Rev. Bras. Zool. 16(4):997-1004.

MAGURRAN, A.E. 1988. Ecological diversity and its measurements. Princeton University Press, Princeton.

MARQUES, O.A.V. 1998. Composição faunística, história natural e ecologia de serpentes da Mata Atlântica, na região da Estação Ecológica JuréiaItatins, São Paulo, SP. Tese de Doutorado, Universidade de São Paulo, São Paulo.

MARQUES, O.A.V., ETEROVIC, A. \& ENDO, W. 2000. Seasonal activity of snakes in the Atlantic forest in Southeastern Brazil. Amphibia- Reptilia, 22(1):103-111.

MARQUES, O.A.V., MARTINS, M. \& SAZIMA, I. 2002a. A new insular species of pitviper from Brazil, with comments on evolutionary biology and conservation of the Bothrops jararaca group (Serpentes: Viperidae). Herpetologica, 58(3):303-312.

MARQUES, O.A.V., MARTINS, M. \& SAZIMA, I. 2002b. A jararaca da Ilha da Queimada Grande. Ciência Hoje, 31(186):56-59.

MARQUES, O.A.V. \& SAZIMA, I. 2003. História natural das serpentes. In Animais peçonhentos do Brasil: biologia, clínica e terapêutica dos acidentes (J.L.C. Cardoso, F.O.S. França, F.H. Wen, C.M.S. Málaque \& V. Haddad Jr., eds.). Savier; Fapesp, São Paulo, p. 62-71.

MARQUES, O.A.V. \& SAZIMA, I. 2004. História natural dos répteis da Estação Ecológica Juréia-Itatins. In Estação ecológica Juréia-Itatins: ambiente físico, flora e fauna (O.A.V. Marques \& W. Duleba, eds.). Holos Editora, Ribeirão Preto, p. 257-277.

MARTINS, M.R.C. 1994. História natural e ecologia de uma taxocenose de serpentes de mata na região de Manaus, Amazônia Central, Brasil. Tese de Doutorado, Universidade de Campinas, Campinas.

MELO, A.S., PEREIRA, R.A.S., SANTOS, A.J., SHEPHERD, G.J., MACHADO, G., MEDEIROS, H.F. \& SAWAYA R.J. 2003. Comparing species richness among assemblages using sample units: Why not use extrapolation methods to standardize different sample sizes? Oikos, 101(2):398-410.

Ministério do Meio Ambiente - MMA. 2002. Biodiversidade brasileira: avaliação e identificação de áreas e ações prioritárias para conservação, utilização sustentável e repartição de benefícios da biodiversidade brasileira. Brasília.

MÜLLER, P. 1968. Die Herpetofauna der Insel von São Sebastião (Brasilien). Saarbrücken Zeitung, verlag und Druckerei GmbH, Germany.

MYERS, N., MITTERMEIER, R.A., MITTERMEIER, G.G, FONSECA, G.A.B. \& KENT, J. 2000. Biodiversity hotspots for conservation priorities. Nature, 403(6772):853-858

NIMER, E. 1977. Climatologia do Brasil. IBGE, Rio de Janeiro.

OLMOS, F. 1991. Observations on the behavior and population dynamics of some Brazilian Atlantic forests rodents. Mammalia, 55(4):555-565.

PEIXOTO, O.L. 1988. Sobre o "status" taxonômicos de Hyla catharinae alcatraz B. Lutz, 1973, com a descrição de uma nova espécie para o grupo "perpusilla" (Amphibia, Anura, Hylidae). Acta Biol. Leopoldensia, 10(2):253-267.

PIANKA, E.R. 1994. Evolution ecology. 5 ed. Harper Collins Publishers, Austin.

POMBAL Jr., J.P. 1997. Distribuição espacial e temporal de anuros (Amphibia) em uma poça permanente na Serra de Paranapiacaba, Sudeste do Brasil. Rev. Bras. Biol. 57(4):583-594.

POMBAL Jr., J.P. \& GORDO, M. 2004. Anfíbios anuros da Juréia. In Estação Ecológica Juréia-Itatins: ambiente físico, flora e fauna (O.A.V. Marques \& W. Duleba, eds.). Holos Editora, Ribeirão Preto, p. 243-256.

REBOUÇAS-SPIEKER, R. 1974. Distribution and differentiation of animals along the coast and on continental islands of the State of São Paulo, Brasil. 2. Lizards of the genus Mabuya (Sauria, Scincidae). Pap. Avul. Zool. 28(12):197-240. 
ROSSA-FERES, D.C. 1997. Ecologia de uma comunidade de anfíbios anuros da região noroeste do Estado de São Paulo: microhabitat, sazonalidade, dieta e nicho multidimensional. Tese de Doutorado, Universidade Estadual Paulista, Rio Claro.

RUSSEL, K.R., GUYNN Jr., D.C., \& HANLIN, H.G. 2002. Importance of small isolated wetlands for herpetofaunal diversity in managed, young growth forests in the coastal plain of South Carolina. For. Ecol. Manage. 163(1-3):43-59.

Secretaria do Meio Ambiente \& Instituto Florestal. 2005. Inventário florestal da vegetação natural do Estado de São Paulo. Imprensa oficial, São Paulo, p. 200.

SAWAYA, R.J. 1999. Diversidade, densidade e distribuição altitudinal da anurofauna de serapilheira da Ilha de São Sebastião, SP. Dissertação de Mestrado, Universidade de São Paulo, São Paulo.

SCHOENER, T.W., SPILLER, D.A. \& LOSOS, J.A. 2001. Predators increase the risk of catastrophic extinction of prey populations. Nature, 412(6843):183-186.

SCOTT Jr., N.J. 1976. The abundance and diversity of the herpetofaunas of tropical forest litter. Biotropica, 8(1):41-58.

VANZOLINI, P.E. 1973. Distribution and differentiation of animals along the coast and in continental islands of the State of São Paulo, Brasil. I. Introduction to the area and problems. Pap. Avul. Zool. 26(24):281-294.

VANZOLINI, P.E. \& REBOUÇAS-SPIEKER, R. 1976. Distribution and differentiation of animals along the coast and on continental islands of the state of São Paulo, Brasil. 3. Reproductive differences between and within Mabuya caissara and M. macrorhyncha (Sauria, Scincidae). Pap. Avul. Zool. 29(15):95-109.
VELOSO, H.P., RANGEL FILHO, A.L.R. \& LIMA, J.C.A. 1991. Classificação da vegetação brasileira, adaptada a um sistema universal. Fundação Instituto Brasileiro de Geografia e Estatística, Rio de Janeiro.

VELOSO, H.P. 1992. Sistema fitogeográfico. In Manual técnico da vegetação brasileira (V.R. Anjos, ed.). Instituto Brasileiro de Geografia e Estatística, Rio de Janeiro, p. 9-38.

VIEITAS, C.F. 1995. Análise ambiental das ilhas da região de Ubatuba (SP) e proposta de manejo para a Ilha do Mar Virado. Dissertação de Mestrado, Universidade de São Paulo, São Paulo.

VITOUSEK, P.M., LOOPE, L.L. \& ANDERSEN, H. 1995. Islands: biological diversity and ecosystem function. Springer-Verlag, New York.

WHITTAKER, R.J. 1998. Island biogeography: ecology, evolution and conservation. Oxford University Press, Oxford.

WILLSON, J.D. \& DORCAS, M.E. 2004. A comparison of aquatic drift fences with traditional funnel trapping as a quantitative method for sampling amphibians. Herpetol. Rev. 35(2):148-150.

WOINARSKI, J.C.Z. \& GAMBOLD, N. 1992. Gradient analysis of a tropical herpetofauna: distribution patterns of terrestrial reptiles and amphibians in Stage III of Kakadu National Parq, Australia. Wildl. Res. 19(2):105-127.

ZEMBRUSCKI, S. 1979. Geomorfologia da margem continental sul brasileira e das bacias oceânicas adjacentes. PETROBRÁS; CENPES; DINTEP, Rio de Janeiro, p. 129-177. REMAC - Relatório final.

Recebido em 29/05/08

Versão Reformulada recebida em 31/03/09

Publicado em 13/04/09 